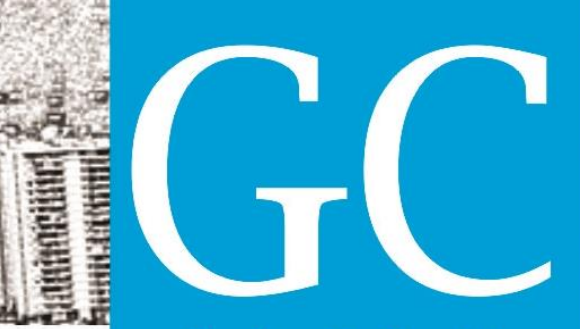

Revista Nacional de Gerenciamento de Cidades

\title{
GEOTECNOLOGIAS LIVRES APLICADAS NO PLANEJAMENTO TERRITORIAL
}

\author{
Eliana Kimoto Hosokawa ${ }^{1}$
}

Diógenes Cortijo Costa ${ }^{2}$

Emília Wanda Rutkowski ${ }^{3}$

\begin{abstract}
RESUMO
A contínua expansão urbana tem gerado inúmeros conflitos de uso da terra e consequentemente, tem causado diversos impactos. A forma de ocupação do solo urbana não associada às políticas públicas influencia negativamente na estrutura das cidades, prejudicando a qualidade de vida urbana. $O$ desenvolvimento de metodologias que permitam rapidez e precisão espacial na análise do território é importante para o processo de tomada de decisão sobre o planejamento territorial. As geotecnologias tornaram-se ferramentas fundamentais não só dos estudos ambientais, mas também do planejamento. Os municípios trabalham com técnicas ineficientes dificultando a produção de informações íntegras, já que não alcançam a análise complexa, dificultando assim o desenvolvimento de planos. A análise do espaço construído possibilita a aquisição de referências visando à compreensão do território. Diante deste cenário, este artigo pretende analisar a potencialidade das geotecnologias livres como ferramenta de apoio ao planejamento territorial.
\end{abstract}

PALAVRAS-CHAVE: Geotecnologias. Planejamento territorial. Sistema de Informação Geográfica.

\section{FREE GEOTECHNOLOGIES APPLIED IN TERRITORIAL PLANNING}

\begin{abstract}
The continuous urban growth has created numerous conflicts of land utilization and consequently has caused several effects. The occupation form of urban land not associated with public policy, negatively influences the structure of cities, damaging the quality urban life. The methodologies development that allows speed and

\footnotetext{
${ }_{1}^{1}$ Aluna de mestrado, Universidade Estadual de Campinas - UNICAMP. eliana.hosokawa@gmail.com 2 Doutor, Universidade Estadual de Campinas - UNICAMP. dcortijo@fec.unicamp.br

${ }^{3}$ Doutora, Universidade Estadual de Campinas - UNICAMP. emilia@fec.unicamp.br
} 
spatial precision over the territory analysis is important for the decision-making process on territorial planning. The geotechnologies have become fundamental tools not only of environmental studies but also for planning purpose. Municipalities work with inefficient techniques hindering the production of straightforward information, since it does not reach the complex analysis, thus hindering the plans development. The analysis of the built environment enables the acquisition of references in order to understand the territory. Given this scenario, this article intends to use free geotechnologies as a support tool on territorial planning.

KEY-WORDS: Geotechnology. Territorial Planning. Geographic Information System.

\section{GEOTECNOLOGÍAS LIBRES APLICADA EN LA PLANIFICACIÓN TERRITORIAL}

\section{RESUMEN}

La expansión urbana continua ha generado numerosos conflictos por el uso de la tierra, causando así diversos impactos. La forma de ocupación del suelo urbano no asociada con las políticas públicas influye negativamente en la estructura de las ciudades, dañando la calidad de vida urbana. El desarrollo de metodologías que agregan velocidad y precisión espacial en el análisis del territorio es importante para el proceso de toma de decisiones en la planificación territorial. Las geotecnologías se han convertido en herramientas fundamentales no sólo en los estudios ambientales, sino también en el planeamiento. Las municipalidades trabajan con técnicas ineficientes que dificultan la producción de información en su totalidad, ya que no logran un análisis complejo, lo que dificulta el desarrollo de los planes. El análisis del espacio construido permite la adquisición de referencias para comprender el territorio. En este contexto, este artículo tiene como objetivo analizar la potencialidad de las geotecnologías libres como herramienta de apoyo a la planificación territorial.

PALABRAS-CLAVE: Geotecnologías. Planificación Territorial. Sistema de Información Geográfica.

\section{INTRODUÇÃO}

A contínua expansão urbana tem gerado inúmeros conflitos de uso da terra e, consequentemente, tem causado diversos impactos ambientais negativos. desenvolvimento de metodologias que permitam rapidez e precisão espacial na identificação e análise destes impactos é importante para o processo de tomada de decisão sobre a gestão urbana.

O Sistema de Informação Geográfica - SIG é uma das geotecnologias que se destaca não só nos estudos ambientais, mas também nos processos de planejamento e gestão: na organização dos temas, no desenvolvimento do banco de dados, na análise espacial, na modelagem de simulações e na construção do projeto. Os SIGs são sistemas que possibilitam organizar referências sobre o 
território de diferentes disciplinas científicas para o estudo de fenômenos ambientais e urbanos. No entanto, poucos municípios têm utilizado esta geotecnologia em virtude da falta de recursos financeiros e capacitação técnica. Com o avanço de softwares livres ${ }^{4}$ e financiamentos do governo federal para modernização da administração pública, sua utilização tem se tornado acessível.

O presente artigo objetiva analisar como as geotecnologias livres podem apoiar o planejamento territorial, para tal, o artigo apresenta fontes de dados geoespaciais para aplicação na análise do espaço construído. A análise qualitativa da utilização de geotecnologias livres representará o arcabouço teórico deste estudo para subsidiar restrições e potencialidades a este tipo de tecnologia.

A geotecnologia pode ser entendida como um conjunto de tecnologias voltadas para a coleta de dados e geração de informação espacializadas. Isso remete às técnicas de sensoriamento remoto, sistema de informação geográfica, cartografia digital, geodésia, sistemas de posicionamento global, topografia, fotogrametria e outras.

As geotecnologias podem ser entendidas como as novas tecnologias ligadas às geociências e correlatas, as quais trazem avanços significativos no desenvolvimento de pesquisas, em ações de planejamento, em processo de gestão, manejo e em tantos outros aspectos relacionados à estrutura do espaço geográfico [...] (FITZ 2008, p.11)

A principal geotecnologia que permite realizar análises mais complexas integrando dados de diversas fontes e criar banco de dados georreferenciados ${ }^{5}$ é o SIG. Este sistema permite que o usuário defina informações relevantes, realize análise espacial, localize geograficamente as informações dos bancos de dados de diferentes setores, compreenda a área de gestão com visão multidisciplinar, acrescente a variável histórica como informação, interagindo os elementos: tempo e espaço.

\footnotetext{
4 Software livre é um aplicativo de computador gratuito, ou seja, aplicativo disponível sem a necessidade de compra da licença de uso ou de atualizações.

${ }^{5}$ Dados georreferenciados são dados portadores de coordenadas geográficas ou planas vinculadas a um sistema de referência.
} 
Revista Nacional de Gerenciamento de Cidades

Fitz (2008) indica que a aplicação prática dos SIGs é a realização de análises de cunho espacial por meio de mapas temáticos diversos. Uma das técnicas trabalha a sobreposição, cada mapa contendo um tema específico, o qual constitui um Plano de Informação (PI). Cada PI é uma camada sobreposta a outra de temática diferente para a obtenção de um produto deles derivado. O mapa temático resultante é analisado com base nos anteriores e os pressupostos metodológicos da ciência geográfica.

O objetivo dos mapas temáticos é fornecer, com o auxílio de símbolos qualitativos e/ou quantitativos dispostos sobre uma base de referência, geralmente extraída dos mapas topográficos ou dos mapas de conjunto, uma representação convencional dos fenômenos localizáveis de qualquer natureza e de suas correlações. (JOLY, 1990, p. 62)

A cartografia permite amparar o processo de elaboração de mapas analíticos dos fenômenos a serem confrontados, pela manipulação experimental dos mesmos por justaposição ou superposição e pela construção de um mapa síntese. 0 resultado deste processo é a compreensão visual das relações territoriais significativas.

Alguns municípios brasileiros fazem uso de banco de dados em formato digital, porém tem dificuldade de utilizá-lo para extrair informações geográficas por falta de conhecimento técnico multidisciplinar. A disponibilização de imagens de sensoriamento remoto gratuitas e softwares SIG livres possibilitaram a produção de informação geográfica a baixo custo com mapas temáticos de qualidade.

Um dos percussores de análise integrada de atributos ambientais foi McHarg (2000). O autor descreve como a identificação do meio físico pode determinar o uso de solo com menor impacto de adaptação, um planejamento ecológico. Apresenta a metodologia de sobreposição de mapas temáticos para identificar os processos naturais e sociais de maior concentração e sua escala de importância.

A maioria dos municípios tem dificuldades de praticar o planejamento territorial, dada à falta de estrutura administrativa, recursos financeiros e condições operacionais. Os governos municipais não possuem instrumentos para orientar o seu crescimento, determinar o zoneamento de uso da terra. No entanto, as 
Revista Nacional de Gerenciamento de Cidades

geotecnologias gratuitas podem possibilitar os municípios no desenvolvimento de seu banco de dados geográficos para obter referências básicas e, assim, analisar o espaço construído.

As principais leis municipais que necessitam de dados do território são Plano Diretor, Lei de Zoneamento e Planta Genérica de Valores.

As principais leis federais que disciplinam a proteção e o uso do meio ambiente são Código Florestal (Lei 12.651/12), Diretrizes da Política Nacional de Mobilidade Urbana (Lei 12.587/12), Estatuto das Cidades (Lei 10.257/01), Lei da Política Nacional do Meio Ambiente - PNMA (Lei 6.938/81), Lei da Política Nacional dos Recursos Hídricos - PNRH (Lei 9.433/97), Lei de Parcelamento Territorial Urbano (Lei 6.766/79), Lei do Sistema Nacional de Unidades de Conservação SNUC (Lei 9.985/2000).

A organização do território exige um diagnóstico preliminar que permita a avaliação das aptidões e das limitações da região. Franco (2008) menciona que todo planejamento inclui a leitura perceptiva da paisagem como indicadora dos pontos de maior significado visual em relação aos aspectos críticos de transformação do relevo, das condições de degradação dos solos, da cobertura vegetal, das características da ocupação urbana e da detecção de vocações paisagísticas.

Segundo Spirn (1995), para proteger as cidades e oferecer melhor qualidade ambiental são necessários bons planos com diretrizes para novos projetos: perceber a cidade como um todo, coletar dados, realizar levantamentos detalhados, interpretar e gerar relatórios, cruzar informações, disponibilizar banco de dados, identificar problemas, formular planos e ações. O ecossistema urbano precisa ser tratado como um todo, atendendo as necessidades dos usuários e vizinhança imediata, se apropriando do conceito de sustentabilidade e usufruindo das características do local. 


\section{Revista Nacional de}

Gerenciamento de Cidades

\section{DESENVOLVIMENTO}

O artigo pesquisou fontes de dados geoespaciais de instituições governamentais que disponibilizam acesso gratuito ao servidor de dados, visando encontrar dados sobre elementos relevantes para o desenvolvimento de planos municipais.

Para demostrar os dados geoespaciais encontrados foi utilizado a Região Metropolitana do Vale do Paraíba para os dados de escala regional e o município de Santo Antônio do Pinhal-SP para os dados de escala municipal (Figura 1).

Figura 1: Localização da RM do Vale do Paraíba e município de Santo Antônio do Pinhal.

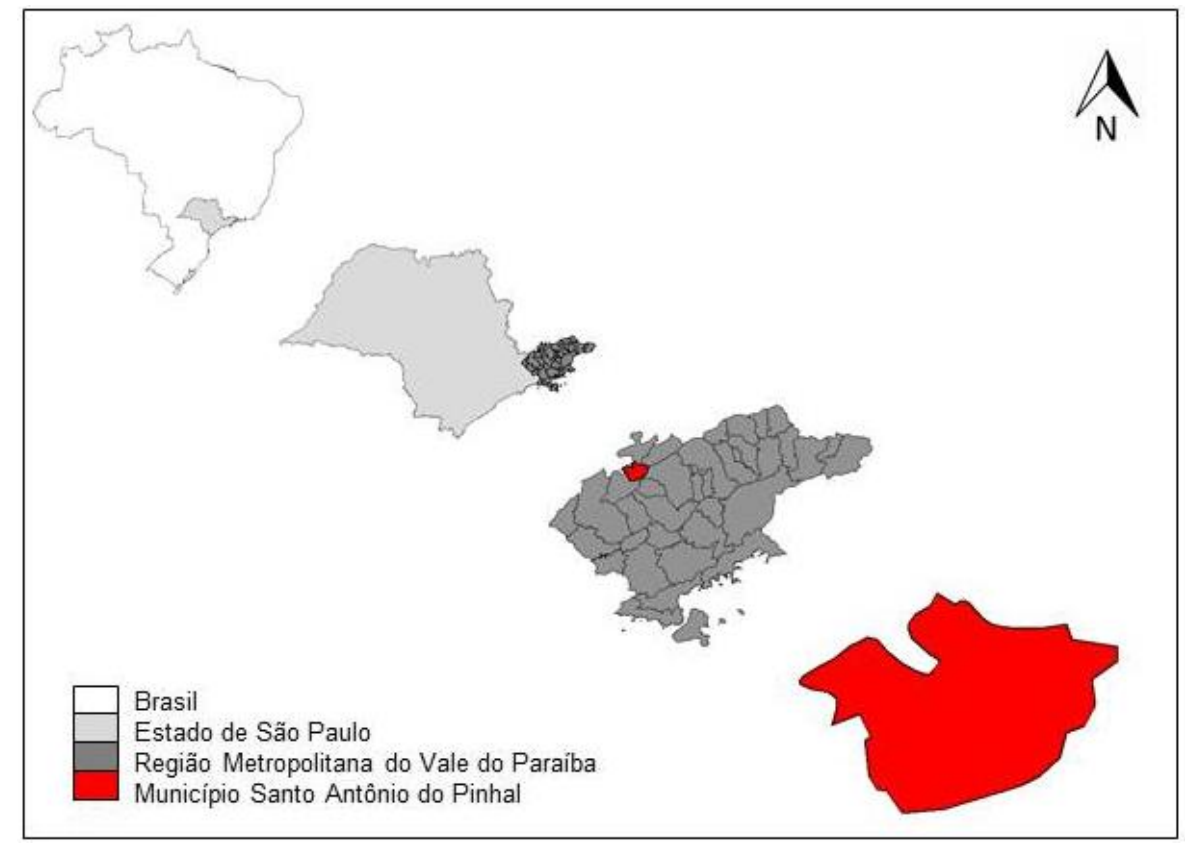

Fonte: IBGE. Elaboração cartográfica: Eliana Kimoto Hosokawa

Todo SIG depende de um banco de dados, para acessar o banco é necessário um Sistema de Gerenciamento de Banco de dados - SGDB que permite coordenação, gerenciamento, integridade, organização dos dados. Todos os aplicativos utilizados no artigo são livres. O SIG utilizado foi o TerraView 4.2.2., disponível em <http://www.dpi.inpe.br/terraview/> e o SGDB utilizado na pesquisa foi o PostrgresSQL 8.4 disponível em: <http://www.postgresql.org/download/> e o 


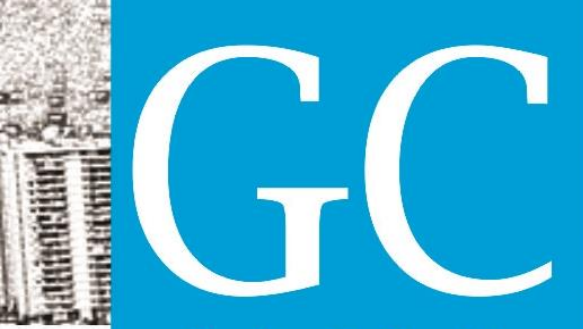

Revista Nacional de

Gerenciamento de Cidades

\section{b. DSG - Diretoria de Serviço Geográfico do Exército Brasileiro}

A DSG é o órgão responsável por superintender as atividades cartográficas no âmbito do Exército Brasileiro em conjunto com o IBGE - Instituto Brasileiro de Geografia e Estatística, entre suas atribuições destacam-se o Mapeamento Sistemático Terrestre Nacional. O Banco de Dados Geográficos do Exército BDGEx é a ferramenta para disseminação de produtos geoespaciais produzidos e/ou adquiridos pela DSG, os dados do DSG estão disponíveis em $<$ http://www.geoportal.eb.mil.br>

O DSG digitalizou e vetorizou ${ }^{6}$ os elementos cartográficos das Cartas do Brasil na escala de 1:50.000, a Figura 3 representa a Carta Tremembé de 1974, onde esta localizado o município de Santo Antônio do Pinhal.

Figura 3: Carta do Brasil Tremembé, em destaque o município de Santo Antônio do Pinhal

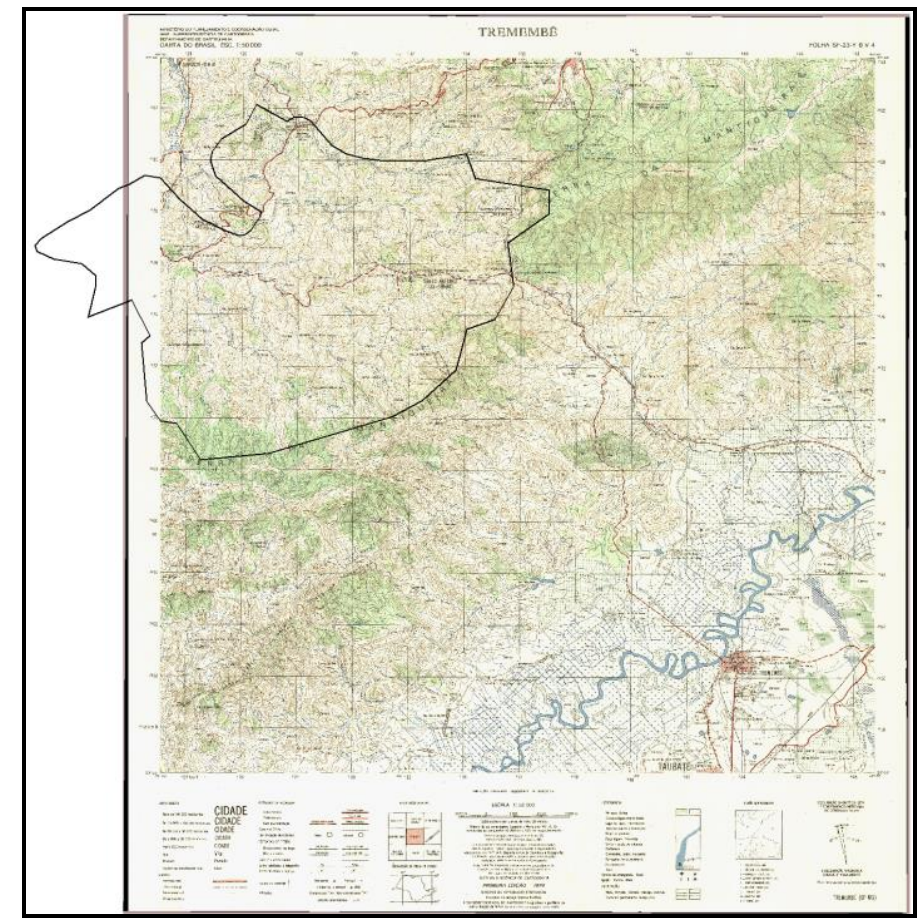

Fonte: DSG. Elaboração cartográfica: Eliana Kimoto Hosokawa

\footnotetext{
${ }^{6}$ Vetorização é o processo de transformar elementos gráficos da forma analógica para a forma vetorial digital. $O$ processo de vetorização diz respeito ao transporte de elementos de uma imagem (carta, fotografia, imagem de satélite) no formato vetorial, realizado por meio de desenho digital. A vetorização pode ser manual, semiautomática ou automática. (FITZ, 2008, p.65)
} 


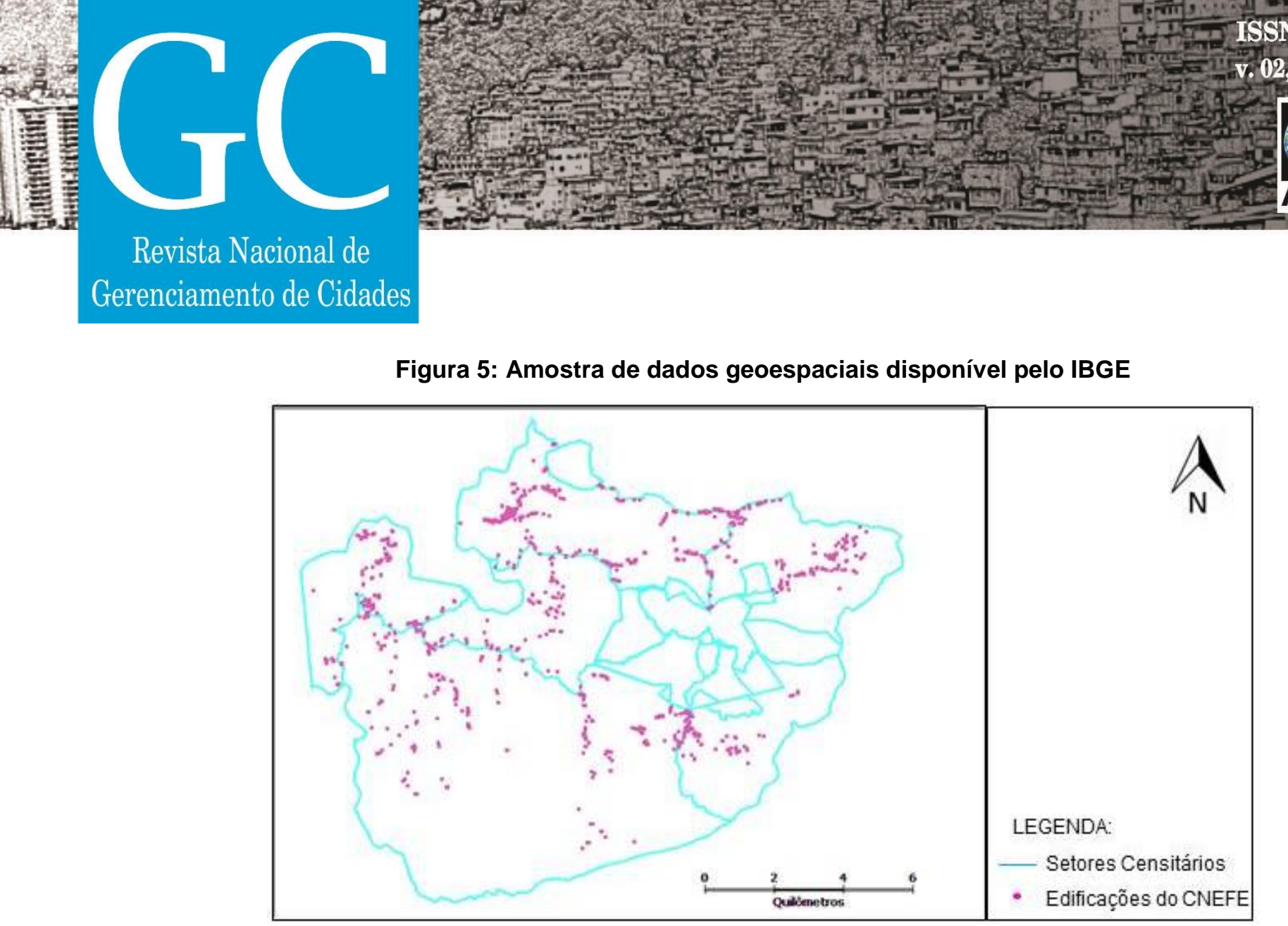

Fonte: IBGE. Elaboração cartográfica: Eliana Kimoto Hosokawa

\section{d. INPE - Instituto Nacional de Pesquisas Espaciais}

A Divisão de Geração de Imagem - DGI do INPE disponibiliza imagens dos satélites Landsat-1, Landsat-2, Landsat-3, Landsat-5, Landsat-7, CBERS-2, CBERS2B, IRS-P6 - Resource-sat1, Aqua e Terra, cada satélite tem seu período de atividade. As imagens destes satélites são gratuitas e disponíveis para download. As imagens mais recentes são do Landsat- 5 com imagens com $30 \mathrm{~m}$ de resolução espacial $^{7}$ do período entre 1984 e 2011. As imagens estão disponíveis em $<$ http://www.dgi.inpe.br/CDSR/>

\footnotetext{
${ }^{7}$ Resolução espacial é a menor área da superfície terrestre observada instantaneamente por cada sensor do satélite, esta informação é importante na interpretação por determinar o nível de detalhe da imagem.
} 


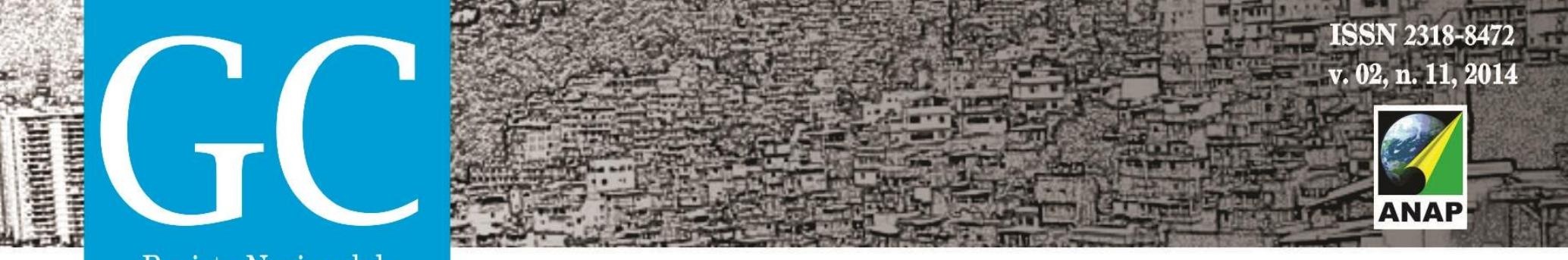

Revista Nacional de

Gerenciamento de Cidades

Figura 6: Imagem do satélite Lansdat-5(2002) Figura 7: Imagem do satélite Lansdat-5(2010)

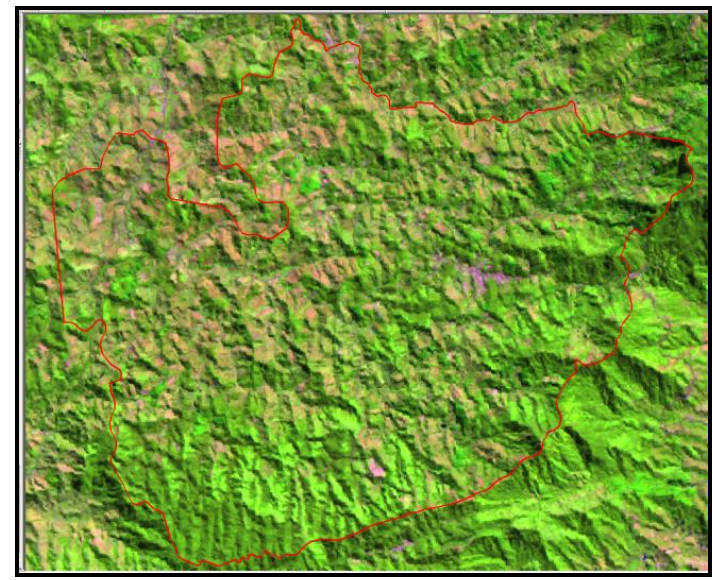

Fonte: INPE, 2002.

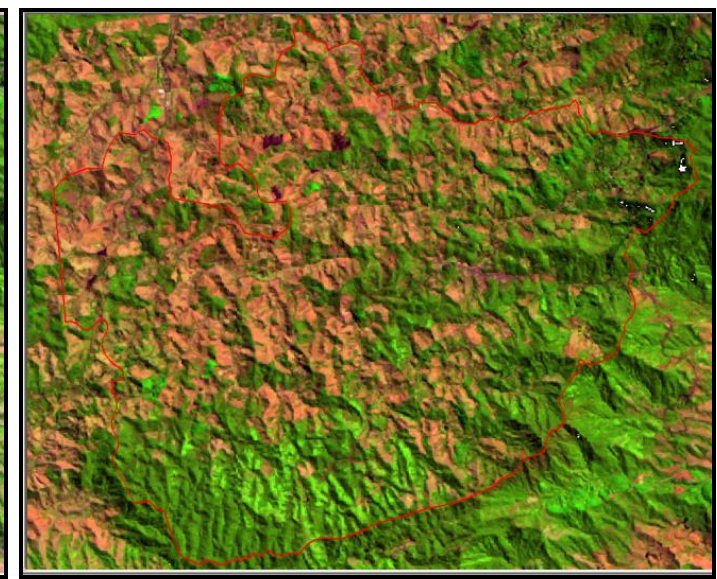

Fonte: INPE, 2010.

As imagens de satélite permitem a visualização do território na sua totalidade e as comparações de imagens de diferentes datas permitem a análise histórica de alterações no município.

\section{e. NASA - National Aeronautics and Space Administration}

A NASA disponibiliza as imagens de satélite Landsat-8 da Terra periodicamente a cada 16 dias, os dados coletados pelo satélite possuem $30 \mathrm{~m}$ de resolução espacial e estão disponíveis para download em $<$ http://earthexplorer.usgs.gov/> 


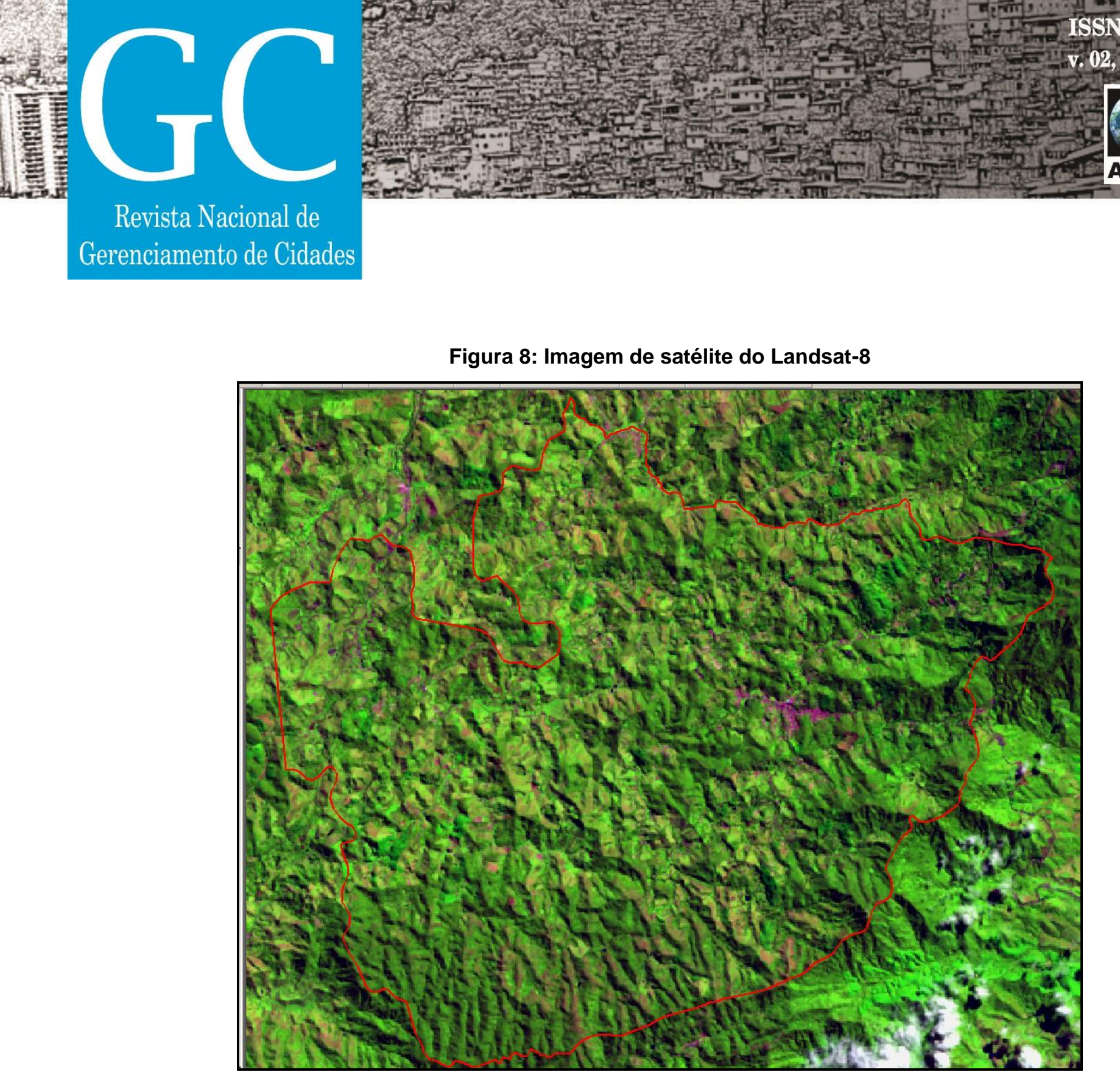

Fonte: NASA, 2014

\section{RESULTADOS}

As fontes de dados geoespaciais podem ser divididas em categorias quanto ao tipo de dados $^{8}$ que disponibilizam: dados vetoriais, matriciais, alfanuméricos. Os metadados geoespaciais contém um conjunto básico de elementos que retratam as características dos produtos geoespaciais de uma instituição e garante a utilização consistente. Os produtos de mapeamento temático requerem o detalhamento dos metadados para a integração de dados provenientes de diferentes fontes $\mathrm{e}$ amarração dos dados contidos no banco de dados geoespaciais.

\footnotetext{
${ }^{8} \mathrm{O}$ dado geoespacial pode ser classificado quanto ao tipo: vetorial (pontos, linhas e polígonos), matricial (imagens) ou alfanumérico (tabela).
} 


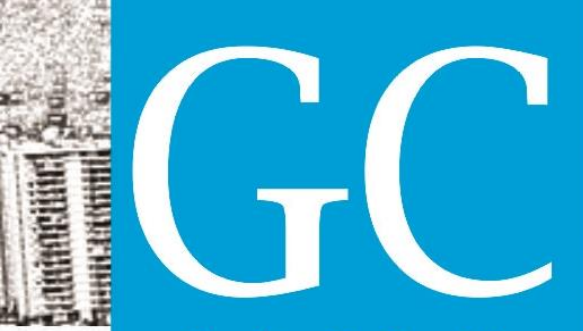

Revista Nacional de

Gerenciamento de Cidades

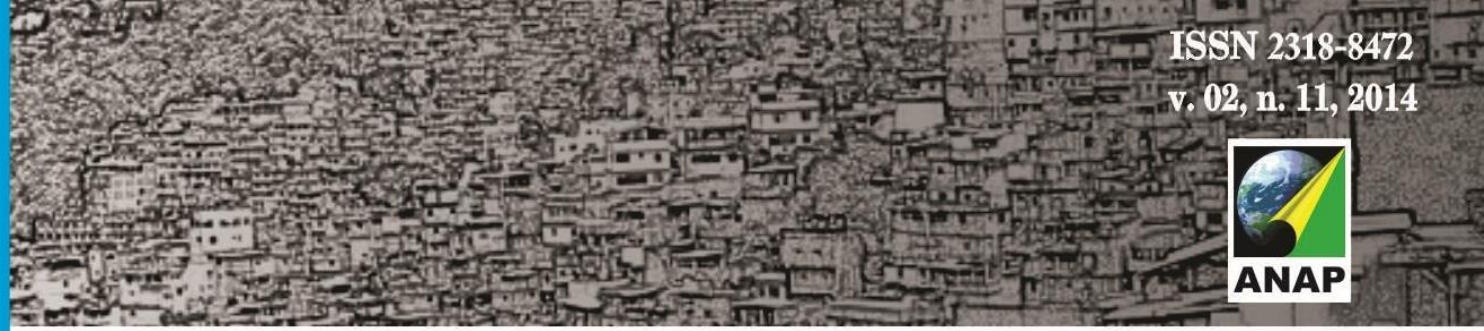

A Tabela 1 apresenta as fontes de dados geoespaciais disponíveis com acesso livre e os metadados mínimos para garantir a utilização consistente dos dados de diferentes fontes e um único banco de dados geográfico.

Tabela 1: Fontes de dados geoespaciais e seus metadados

\begin{tabular}{|c|c|c|c|c|c|}
\hline Fonte & Tipo & Ano & Escala & Projeção & Área \\
\hline BIT & vetor & 2009 & 1:1.000.000 & Latlong/SIRGAS2000 & Brasil \\
\hline DSG & vetor e matricial & 1974 & 1:50.000 & Latlong/WGS84 & Brasil \\
\hline IBGE & vetor & 2010 & 1:25.000 & Latlong/SIRGAS2000 & Brasil \\
\hline Fonte & Tipo & Ano & Resolução Espacial & Projeção & Área \\
\hline INPE & imagem & 2011 & $30 \mathrm{~m}$ & Latlong/SAD69 & Terra \\
\hline NASA & imagem & 2014 & $30 \mathrm{~m}$ & UTM/WGS84 & Terra \\
\hline
\end{tabular}

Um banco de dados geográfico apresenta dados qualitativos e quantitativos sobre imagens de satélite (Figura 9) em forma de representações gráficas ou de atributos alfanuméricos vinculados às representações gráficas. Para permitir variadas combinações de consultas fundadas nos valores dos atributos e nas relações espaciais entre as geometrias.

Figura 9: Amostra de dados geoespaciais disponíveis com acesso livre pela DSG e IBGE sobre imagem de satélite Landsat-8

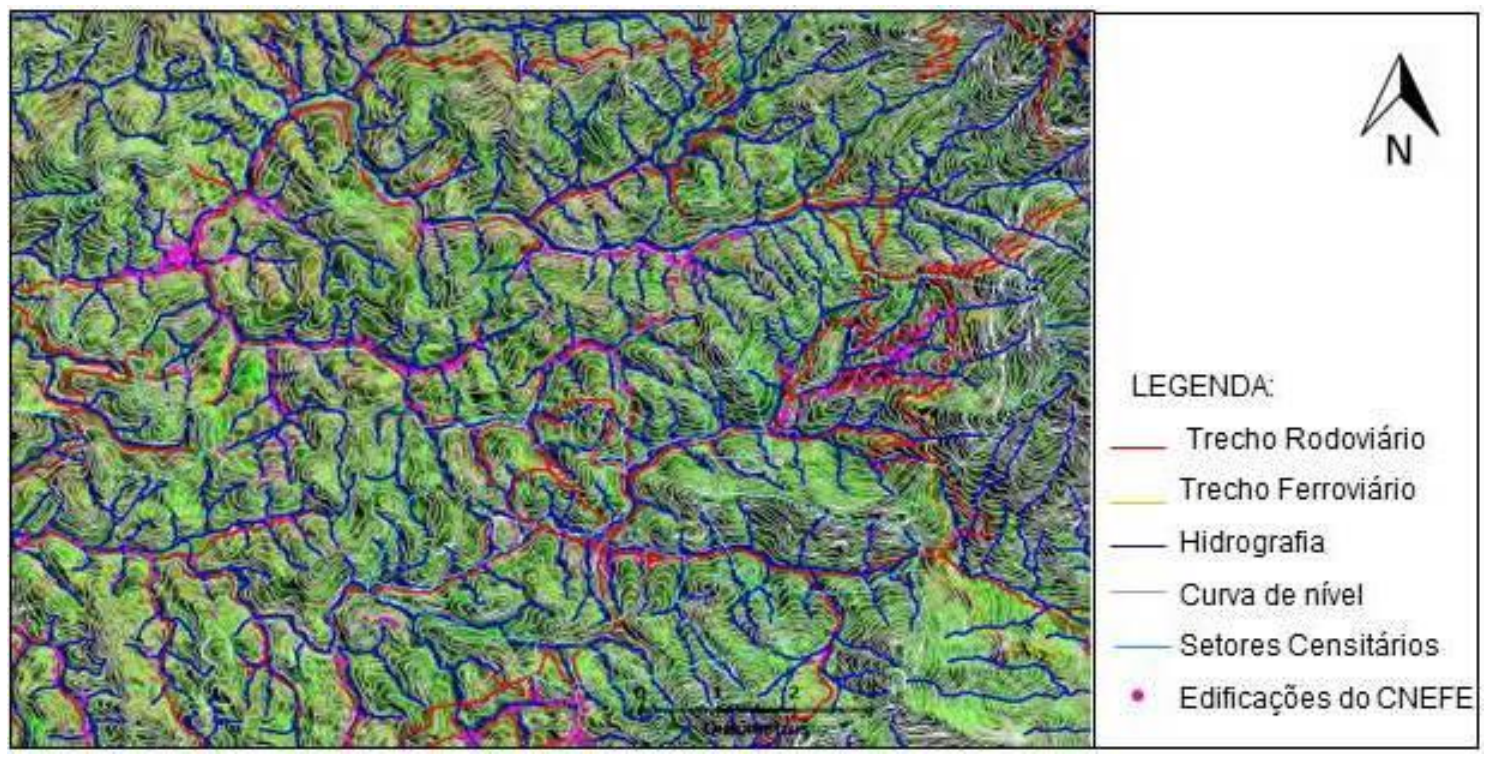

Fonte: DSG, IBGE e NASA

Elaboração cartográfica: Eliana Kimoto Hosokawa 
Os dados geoespaciais apresentados na Tabela 1 não estão na escala adequada para planejamento urbano municipal, no entanto, os dados geoespaciais levantados gratuitamente neste estudo servem de referência aos municípios que não possuem nenhum tipo de dados geográficos georreferenciado do seu território. As escalas adequadas para desenvolvimento de planejamento territorial é de 1:500 a 1:10.000, conforme NBR 14.166/1998. Esta norma estabelece o Sistema Cartográfico Municipal como um conjunto de documentos cartográficos estruturados a partir da implantação da Rede de Referência Cadastral para o levantamento de informações territoriais no âmbito municipal.

\section{CONCLUSÃO}

Alguns municípios que utilizam as geotecnologias têm dificuldade de extrair informações por falta de recurso técnico de profissionais como agrônomos, arquitetos urbanistas, biólogos, engenheiros, geógrafos e geólogos. Os SIGs dependem de métodos científicos que auxiliem o observador a definir correlações de fenômenos de qualquer natureza no território, para então processar os dados e obter informação como resultado. A pesquisa demonstrou como geotecnologias gratuitas podem apoiar os municípios a desenvolver seu banco de dados geográficos para obter referências básicas para análise do espaço construído, apoiando assim planejamento territorial.

As geotecnologias realizam tarefas complexas, possibilitando a elaboração de mapas, cartas e plantas topográficas com rapidez, exatidão/precisão e a diminuição dos custos na elaboração desses produtos que são de fundamentais para tomada de decisão. Para a geração dos mapas temáticos é necessário o uso de outras bases cartográficas, a qualidade do produto final é o reflexo da base de dados de origem. Em determinados casos é possível reduzir a escala em relação ao mapa original, entretanto, a escala não deverá ser aumentada.

As instituições governamentais ou privadas disponibilizam pela internet o acesso de seus bancos de dados geoespaciais, que são fontes de dados 
Revista Nacional de Gerenciamento de Cidades

importantes que devem ser utilizados com o conhecimento dos metadados para garantir a extração de informações com qualidade.

Almeida, Câmara e Monteiro (2007) expõem que não basta somente a confecção de mapas coloridos, é fundamental a análise espacial para extrair tendências do padrão de manifestação do fenômeno, entendendo sua proliferação no espaço e no tempo em articulação com inúmeras variáveis socioeconômicas e biofísicas. A informação deve estar apoiada em estruturas de percepção ambiental que proporcionem eficiência em seu objetivo de fundamentar abordagens científicas, transformando dados geograficamente referenciados em conhecimento.

As geotecnologias são ferramentas fundamentais para obter referências básicas do espaço construído, portanto atende todos os profissionais que trabalham na área de gestão e planejamento territorial, entre eles, o arquiteto urbanista. $A$ Resolução $n^{\circ}$ 21/2012 do Conselho de Arquitetura e Urbanismo do Brasil (CAU/BR) dispõe sobre suas as atividades e atribuições, entre as atividades listadas encontram-se as referentes ao georreferenciamento e topografia, no qual o profissional possui as seguintes atribuições: levantamento topográfico por imagem, fotointerpretação, georreferenciamento, levantamento topográfico planialtimétrico, análise de dados georreferenciados e topográficos cadastro técnico multifinalitário e elaboração de Sistemas de Informações Geográficas - SIG.

\section{REFERÊNCIAS}

ALMEIDA, C. M. de A.; CÂMARA, G. e MONTEIRO, A. M. V. Geoinformação em Urbanismo: cidade real $\mathbf{x}$ cidade virtual, 1ed, São Paulo: Oficina de Textos, 2007. 368p

ASSOCIAÇÃO BRASILEIRA DE NORMA TÉCNICA. NBR 14.166. Rio de Janeiro, 1998.

CONSELHO DE ARQUITETURA E URBANISMO DO BRASIL. Resolução $n^{\circ} 21$, de 5 de abril de 2012. Brasília. Disponível em: <http://www.caubr.gov.br/anexos/resolucao/RES21_CAUBR_16_2012.pdf >. Acesso em 14 de jul. de 2014.

DIRETORIA DE SERVIÇO GEOGRÁFICO DO EXÉRCITO BRASILEIRO (DSG). Geoportal do Exército Brasileiro. Brasília. Disponível em: <http://www.geoportal.eb.mil.br>. Acesso em: 14 mai. 2014.

FITZ, P.R. Geoprocessamento sem complicação, 1ed, São Paulo: Oficina de Textos, 2008. 160p. 
